\title{
Brightening the Mind: The Impact of Practicing Gratitude on Focus and Resilience in Learning
}

\author{
Jane Taylor Wilson ${ }^{1}$
}

\begin{abstract}
A growing body of groundbreaking research shows that gratitude has the power to heal, energize, and transform lives by enhancing people psychologically, spiritually, physically, and cognitively. This study contributes to the study of gratitude by exploring its impact on focus and resilience in learning. Specifically, this study examines the impact that practicing gratitude has on college students' ability to focus in class and remain resilient in the face of difficulties while learning.
\end{abstract}

Keywords: gratitude, learning, focus, resilience, teaching, positive psychology

Recent research on gratitude shows significant benefits to a person's overall well-being and ability to flourish in life psychologically, spiritually, and physically. Gratitude may carry cognitive benefits as well, though such research is limited. To gain a deeper understanding of the cognitive benefits of gratitude, the researcher of this study wondered if college students who practice gratitude on a consistent basis would experience increased ability to focus while learning and remain resilient when learning felt challenging. This study measures 110 college students' self-assessment of gratitude, focus, and resilience in learning, and then examines changes over time produced from an intervention. An intervention group of 50 college students were consistently reminded and encouraged to engage in gratitude practices related to their learning. The reminder to practice gratitude came in the form of text messages that were sent every 4-5 days for three months. The control group of 60 college students did not receive any text messages. Those students who received reminder texts to practice gratitude, the researcher hypothesized, would experience greater benefits for focus and resilience in learning than those who did not receive reminder texts. The results of this study indicate that providing reminders to intentionally practice gratitude toward learning may increase students' ability to focus in class and to remain resilient while facing difficulties in learning.

\section{Literature Review}

\section{The Growing Field of Gratitude}

As the $20^{\text {th }}$ century came to a close, the president of the American Psychology Association, Martin Seligman, offered a charge to reexamine traditional psychological emphasis on exploring dysfunctions and abnormalities of human behavior and shift some attention toward human behaviors that lead to worthwhile and satisfying lives. This fresh lens led to the emergence of a new branch of psychology-Positive Psychology—-that explores conditions which promote optimal human flourishing (Seligman and Csikszentmihalyi, 2000). In its first fifteen years this new field grew at an impressive rate

\footnotetext{
${ }^{1}$ Department of Education, Westmont College, 955 La Paz Road, Santa Barbara, CA, 93105, jawilson@ westmont.edu
} 
with the birth of 20 new graduate programs (including University of Pennsylvania and Claremont), large grants, a Journal of Positive Psychology, the International Positive Psychology Association, and the Greater Good Science Center (affiliated with University of California at Berkeley), resulting in 1300 peer-reviewed academic articles (Donaldson, S, Dollwet, M. \& Rao, M, 2015). Early on, researchers identified 24 character strengths that help people lead meaningful and flourishing lives, classified under the categories of wisdom, courage, humanity, justice, temperance, and transcendence (Peterson \& Seligman, 2004). Of the 24 character strengths, gratitude, hope and resilience have been the most scientifically studied (Donaldson, et al, 2015). As a character strength, gratitude refers to an ability to recognize and appreciate the benefits received from others and a desire to reciprocate with positive actions (Emmons, 2007). Those who possess this character strength have a deep awareness and acknowledgement of the good in their lives.

An interdisciplinary group of professionals doing groundbreaking research on gratitude gathered for a 2014 Greater Good Science Center Gratitude Summit as a culmination of their "Expanding the Science and Practice of Gratitude" project, funded by the John Templeton Foundation. Robert Emmons (2014) opened the Gratitude Summit with the proclamation, "Gratitude has the power to head, energize, and transform lives." Researchers then described their cutting-edge research illuminating the critical role gratitude plays in overall well-being, in the workplace, in schools, and in relationships. Overwhelmingly, the recent research presented at the conference and published in articles demonstrates that gratitude enhances lives psychologically, socially, spiritually, physically, and cognitively (Emmons \& McCullough, 2004; Seligman, Steen, Park, \& Peterson, 2005; Wood, Froh, \& Geraghty, 2010).

Psychologically, people who reflect and reframe their experience from a perspective of gratitude experience more positive emotions, lower levels of stress, and healthier relationships (Duckworth, Steen, \& Seligman, 2005; Watkins, Cruz, Holben, \& Kolts, 2008; Watkins, Uhder, \& Pichinevskiy, 2014; Wood, Joseph, \& Maltby, 2009). Socially, gratitude appears to strengthen relationships by promoting relationship formation and maintenance as well as the perceived sense of support, help, and collaboration (Algo, Haidt, \& Gable, 2008; Wood, Maltby, Gillett, Linley \& Joseph, 2008). Gratitude is a central pillar of most religions, thus it is not surprising that spiritually, grateful people experience greater connection to God and more peace and contentment (Emmons, 2007). Physically, grateful people experience more energy, healthier hearts, better sleep, and even increased longevity (Emmons \& McCollough, 2003; McCraty, \& Childre, 2004; Wood, Joseph, et all. 2009). Cognitively, it appears, grateful people are more alert, focused, creative in problem-solving, and appreciative of learning (Howells, 2012; Wilson \& Harris, 2014).

\section{Gratitude as a Learned Trait}

Researchers have investigated whether gratitude is a genetic disposition or learned trait. Lyubomirsky, Sheldon, and Schkade (2005) argue that 50\% of one's tendency toward happiness is related to one's genetic set point, $10 \%$ to circumstance, and $40 \%$ to intentional activity. Psychologists have identified a group of intentional activities, called "gratitude practices," that can be used to strengthen one's level of happiness or gratitude. When people intentionally chose to engage in gratitude practices, researchers have found that practitioners experienced an overall enhanced sense of well-being (Emmons \& 
McCoullough, 2003). Though gratitude might not come naturally to some people, it can be learned with a certain level of introspection and reflection (Froh, Miller, and Snyder, 2007). For example, researchers found that participants who daily recounted blessings were training their brains with cognitive habits which amplified the good in their lives (Watkins et al, 2014). It appears that gratitude can be cultivated with intentional practice.

\section{Gratitude Practices}

In the recent literature, a number of gratitude practices have emerged that help people strengthen their ability to be thankful. All of these practices invite people to stop and notice blessings, savor blessings, speak of blessings, and respond in some manner.

Gratitude journal. To engage in this gratitude practice, one identifies and records 3-5 specific blessings on a daily or weekly basis. This practice of gratitude journaling tends to be more effective when participants focus on gratitude for people rather than material objects, take time to savor each blessing, and remain open to surprises in their lives (Emmons \& McCollough, 2003; Seligman, 2012; Seligman, et al., 2005).

Gratitude letter. In this gratitude practice, one selects an individual whom he or she has never properly thanked and then writes that person a letter (approximately 300 words) that expresses specific thanks. Research suggests that writing, delivering, and receiving a gratitude letter can enhance joy for both the author and the receiver (Froh, Kashdan, Ozimkowski, \& Miller, 2009: Seligman et al., 2005).

Gratitude conversation. This gratitude practice occurs when people intentionally engage in conversation with others about positive events, experiences, or outcomes that happen each day. By expressing gratitude about these events, people broaden and build their social bonds with others, which leads to community strength and harmony (Fredrickson, 2004).

State of Preparedness. This gratitude practice specifically invites students to examine their attitudes regarding a class and honestly assess their personal outlook. The State of Preparedness practice asks students to determine if they hold attitudes of gratitude or resentment, and then encourages them to consciously choose a grateful perspective (Howells, 2012).

\section{Gratitude's Relationship to Focus and Resilience in Learning}

A growing number of academics, educators, and thought leaders suggest that gratitude is one of seven character strengths (i.e., gratitude, grit, zest, self-control, optimism, social intelligence, and curiosity) predictive of student success in academic settings (KIPP, n.d.; Seligman, Ernst, Gillham, Reivich \& Linkins, 2009; Tough, 2011). Knowledge is Power Charter Schools (KIPP) developed a character report card (grounded in the research of Chris Peterson, Martin Seligman, and Angela Duckworth) to hold students accountable in demonstrating these non-cognitive skills. Duckworth's lab at the University of Pennsylvania created a Character Lab (characterlab.org) to develop, disseminate, and support research-based approaches to character development that enable students to flourish as learners. Recently, researchers have empirically established the relationship between multiple dimensions of character strengths and schools outcomes longitudinally (Park, Tsukayama, Goodwin, Patrick \& Duckworth, submitted for publication). These 
findings align with the theoretical claim that schools should promote three domains of character-interpersonal character, intellectual character, and intrapersonal character - to enhance success in school settings (Pellegrino \& Hilton, 2012). Specially, interpersonal character includes gratitude, social intelligence, and interpersonal self-control; intellectual character includes curiosity and zest; and intrapersonal character includes academic selfcontrol and grit. To date, however, only one book focuses specifically on gratitude in education (Howells, 2012). In this book, Howells presents gratitude as a pedagogical strategy underlying effective instruction and argues that when students thank when they think they think in more engaged ways.

Focus in Learning. Howells (2012) argues that students want to be focused learners, but do not know how to do so. In her university courses, Howells guides students to examine the impact of a grateful attitude in contrast to one of complaint or resentment. When students enter class with a spirit of complaint, this attitude limits their ability to think, concentrate, integrate information, or see value in learning. In contrast, when students enter class with an attitude of gratitude, they are more engaged, focused, and motivated to exert effort toward learning. Howells encourages students to take charge of their own attitudes by reserving a minute at the beginning of class to be aware of their attitude and mindfully choose a grateful spirit. Howells dubbed this gratitude practice "A State of Preparedness" (Howells, 2012).

Resilience in Learning. Growth mindset, a term coined by Stanford Professor Carol Dweck (2006), is the belief that intelligence grows through effort. Students with a growth mindset remain resilient and persevere in the face of setbacks since they view challenges as an opportunity to learn and grow. Closely connected to growth mindset is the character strength of grit, which is the ability to persevere in confusing or challenging situations in order to reach a long-term goal (Duckworth, Peterson, Matthew, \& Kelly, 2007). Achievement is the product of hard work and effort, and those who are grateful for challenges, who work harder, and who are more able to cope with obstacles possess the grittiness needed to succeed in academic and life settings (Duckworth et al., 2007). Since challenges in learning often produce stress, educators need to help students have effortful control of the brain, a skill set that includes "the ability to control reactions to stress, maintain focused attention, and interpret mental states in themselves and others" (Duckworth \& Allred, 2012, p. 628).

\section{Methodology}

The purpose of this study is to explore the impact of practicing gratitude on college students' ability to focus in learning and remain resilient when learning feels challenging. The participants, 110 college students, were chosen for accessibility. All participants were serving in some campus leadership role and arrived on campus early for a week of orientation activities. Upperclassmen represented $80 \%$ of the sample; $20 \%$ were in their second year. Females represented 67\%; males represented 33\%. Fifty-eight percent of the participants identified as white; $42 \%$ identified as people of color.

The (GQ-6) Gratitude Questionnaire-Six Item Form (Emmons, McCullough, \& Tsang, 2003) was used to measure levels of gratitude. This tool was modified to include an additional six questions investigating focus in learning as well as six more questions investigating resilience in learning. In total, the revised inventory involved 18 questions. 
The 110 participants completed this 18-question inventory at a late August orientation meeting for student leaders the week prior to the 2015 fall semester. An intervention group of 50 students agreed to receive reminder text messages once or twice weekly throughout the semester; the control group did not receive reminders. In early December, near semester's end, all 110 students were invited via email to complete the same 18-question inventory; $84 \%$ of intervention group and $58 \%$ of control group completed the inventory. Two additional optional questions were added to the December inventory: 1) How often did you engage in gratitude practices? Daily? Twice/week? Weekly? Once/twice each month? 2) Do you have additional insights you would like to share with the researchers?

The 50 students who agreed to receive reminders were sent 22 text messages from a Mighty Text app, which allowed for group text messages to be sent to each person individually. Reminders were sent twice one week (i.e., at the beginning and end of the week), then at the middle of the following week. Though the content of each text message varied slightly, the reminders observed the following pattern:

- Beginning-of-week reminder: Gratitude nudge-Take a minute at the beginning of a class and choose to have a grateful attitude for the class.

- End-of-week reminder: Gratitude nudge-Reflect back on the week and ponder 35 specific blessings related to learning. Take time to savor those blessings.

- Middle of week reminder: Gratitude nudge-Think about your professors or fellow students who are helping you learn. Express thanks to them.

\section{Findings}

Analysis of the data revealed that students who received reminders to practice gratitude toward learning and then intentionally practiced gratitude self-reported an increase in their level of gratitude, their ability to focus during class, and their ability to remain resilient when learning felt more challenging.

The following three charts track such changes over the fall semester. The leftmost bar on each chart shows the collective score of all 110 participants gathered in late August; bars proceeding to the right represent distinct group scores in early December. The December groups are as follows:

1) students who received gratitude text messages and identified that they practiced gratitude at least three times per week $(n=22)$

2) students who received the gratitude text messages and identified that they practiced gratitude less than once per week $(n=20)$

3) students who did not receive the text messages and identified that they practiced gratitude at least three times per week $(n=17)$

4) students who did not receive the text messages and identified that they practiced gratitude less than once per week $(n=18)$

\section{Chart A. Change in Gratitude}




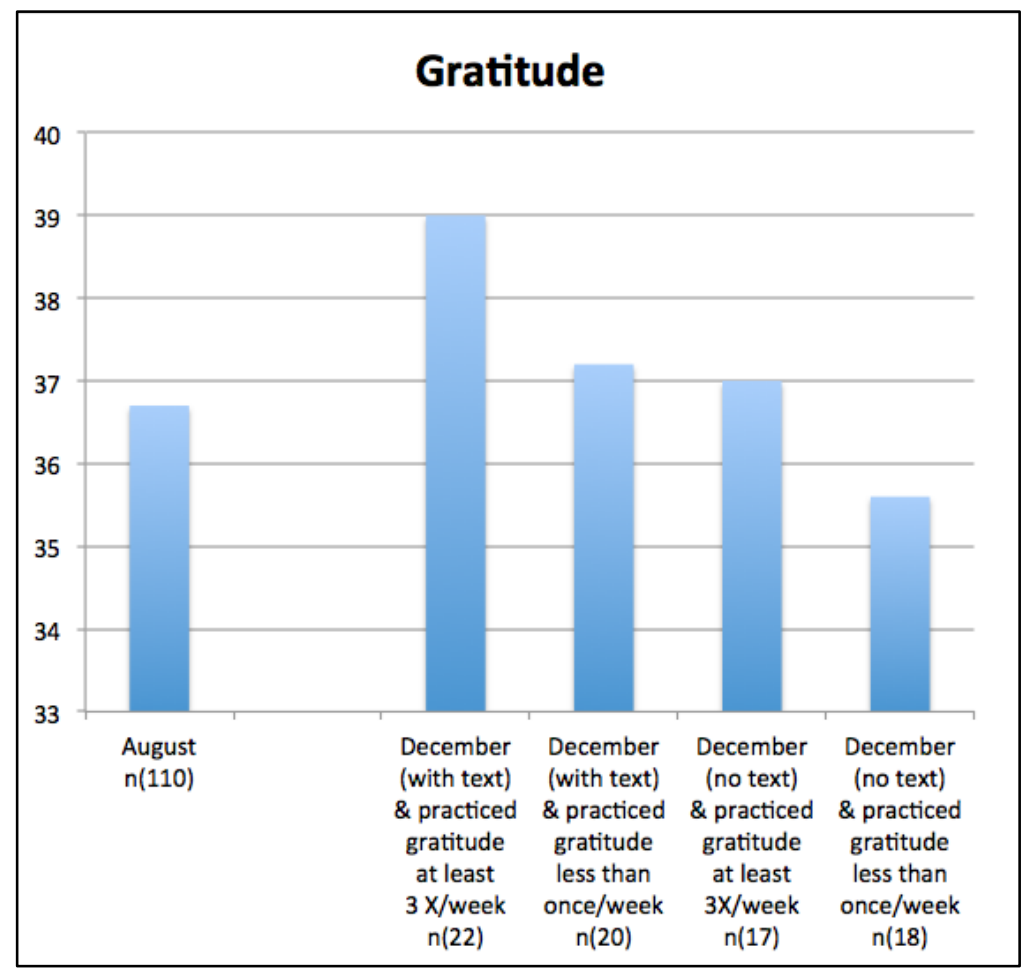

\section{Chart B. Change in Focus in Learning}

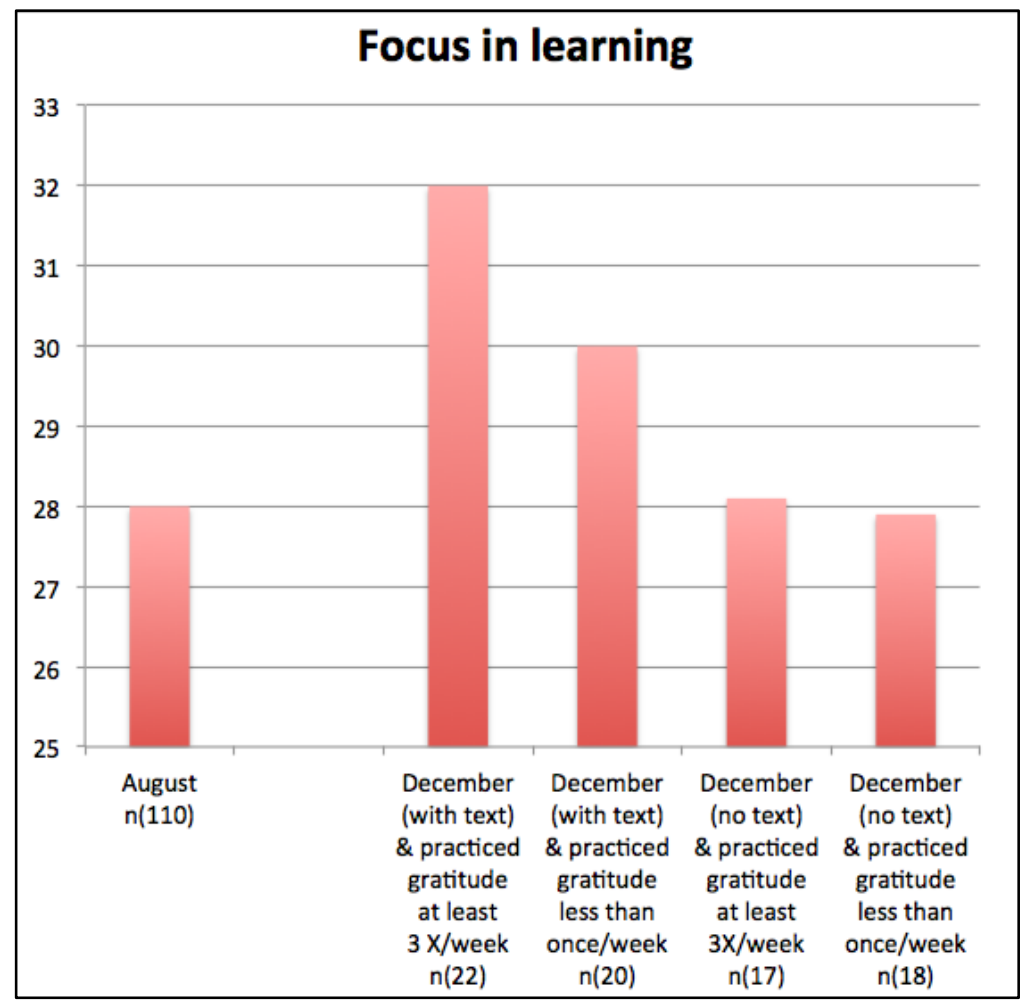

\section{Chart C. Change in Resilience in Learning}

Journal of the Scholarship of Teaching and Learning, Vol. 16, No. 4, August 2016.

josotl.indiana.edu 


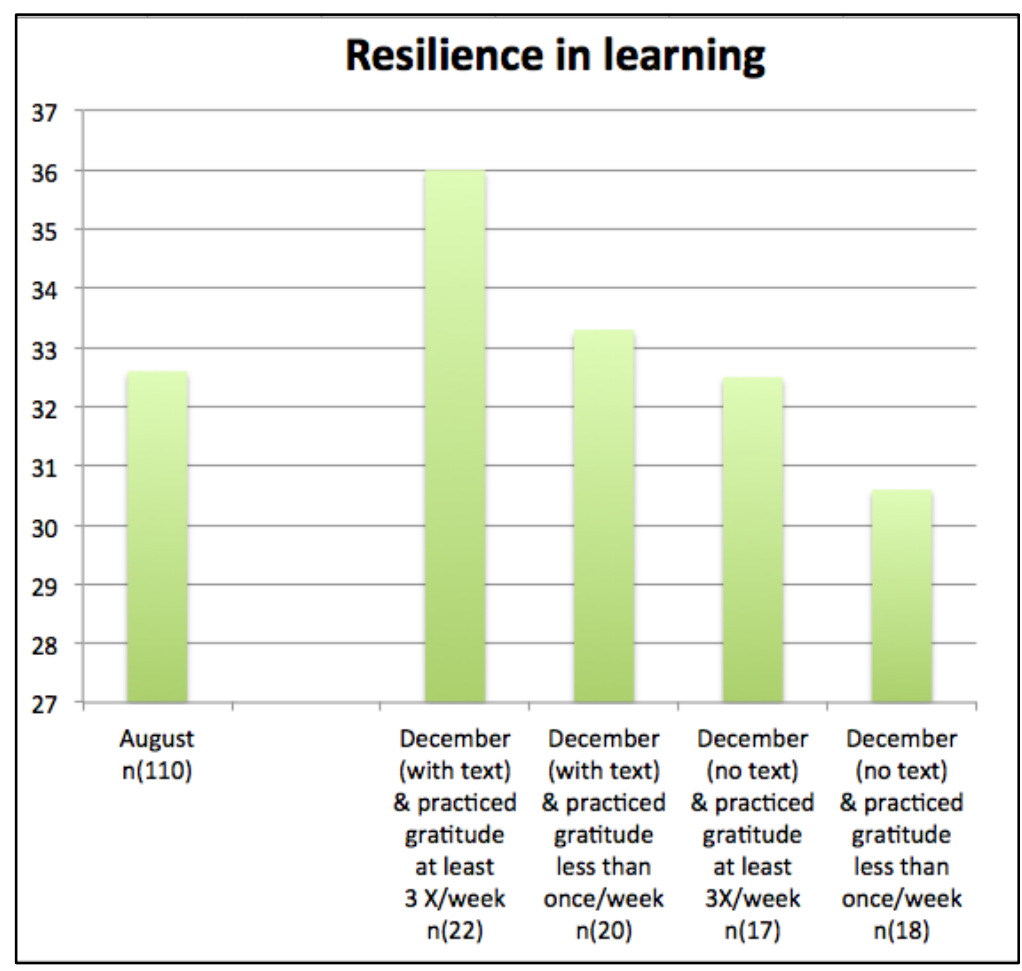

Of the four bars representing December results, the left two bars show results from the intervention group - students who received text message reminders to practice gratitude toward learning. In this group, students who practiced gratitude at least three times weekly tended to report an increase in their level of gratitude, their ability to focus, and their ability to remain resilient in learning. There was only a slight increase in students who selfreported practicing gratitude less than once each week.

The right two columns represent December results from the control group -students who did not receive reminders to practice gratitude. Students who self-reported that they intentionally practiced gratitude at least three times weekly saw no change in their score; whereas students who self-reported practicing gratitude less than once each week saw a decline in their level of gratitude and their ability to remain resilient in learning.

\section{Emerging Themes}

The end-of-semester inventory included an optional question, "Do you have any additional insights to share with the researchers?" Eighty percent of participants who received text message reminders to practice gratitude responded to this open-ended question, whereas only a scattering of responses were received from participants who did not receive the text message reminders. These written comments provide rich detail to support the quantitative results of the inventory. Using a ground theory of analysis to examine these comments (Strauss \& Corbin, 1990), themes emerged that may influence students' ability to focus and remain resilient while learning. Each theme builds upon or extends the previous theme.

Positive and calm attitude. Emerging as the most prominent theme when participants intentionally practiced gratitude was a positive shift in attitude. Comments such as "I noticed life gets a bit brighter," "My entire attitude changes which I explicitly 
practice gratitude," and "I found that practicing gratitude gave me a more positive outlook on learning" evidenced this positive shift. As a result of practicing gratitude, 21 students referred to feeling "positive," "happier," "joyful" or "calmer." Such brightened attitudes seemed to affect participants' lives broadly, e.g.: "After practicing gratitude daily, I take joy in so much more, and I feel like I am really living life rather than just getting through each day." Similarly, another student expressed, "Practicing gratitude impacts every aspect of my life, not just my academics. I feel better about life as a whole now, not just my schoolwork."

Lessened stress. This positive shift in attitude was likely related to a second effect or theme: lower stress. Twelve participants expressed experiencing reduced stress levels when they practiced gratitude toward learning. Two participants wrote about this effect as follows: "Stressful aspects of learning were shown to be small in the light of gratitude" and "Practicing gratitude quelled anxieties related to schoolwork." Similarly, many explicitly pointed to gratitude as a tool that that helped reduce stress: e.g., "Gratitude pulled me out of the pit of negativity and stress" and "One day I was stressed and anxious and overwhelmed but after I took a moment to list a few things to be grateful for, my approach to the day changes drastically." In particular, a few other students commented that they experienced lessened stress during exams when they intentionally practiced gratitude. Six participants reported experiencing better sleep when they practiced gratitude before going to bed, which may be related to reduced stress level. As expressed by two students, "I fell asleep more quickly" and "it relieved my anxieties so it was easier to fall asleep."

Focus in learning. Equipped with a positive spirit, lessened stress levels, and better sleep, it is not surprising that participants who intentionally practiced gratitude toward learning self-reported increased focus while learning. Ten participants stated that gratitude helped them "focus better" and one clarified, "When I was zoning out because I was bored or ungrateful, then gratitude would increase my focus." Another student admitted that gratitude was helpful in focusing on their education "at least for the short term." One participant noticed the reflective impact of a more positive attitude: "I noticed much more of an awareness in my attitude toward my thinking and studying." Moreover, a few students reported that gratitude heightened their awareness of the "purpose of learning" which heightened their focus. When stress levels were reduced, apparently due to practicing gratitude, four students expressed being able to think more clearly during exams-e.g., "Practicing gratitude right before an exam eased my anxiety and I could think and focus better on the exam."

Effort amidst challenges. A positive spirit, lessened stress, and increased focus helped students feel motivated to exert effort toward learning, especially when learning felt challenging. As reported by two students, practicing gratitude helped them "stay motivated while challenged with a list of things to accomplish" and "put longer hours and harder work toward schoolwork with a more positive attitude." When students experienced lessened stress, they also reported an increased ability to remain resilient. One participant explained, "When I practiced gratitude, I become less stressed and more willing to push forth and complete any tasks that seemed long and tedious." In addition, eight students noticed a shift in attitude specifically related to challenges while learning. One student wrote, "Gratitude helped me have a better perspective on the challenges I faced in my learning." "Instead of being bitter," explained another student, "I am more open to challenging 
situations." "Challenging situations were eased when I focused on being grateful that challenges help me grow," noted yet another.

Though these four themes-positive and calm attitude, lessened stress, focus in learning, effort amidst challenges - are listed separately, the themes build upon and extend one another. When students experienced a more positive and calm attitude, they reported that their stress levels reduced. With a more positive attitude and reduced stress, these students self-reported that they were better able to focus in learning and continue to exert effort even when the learning felt challenging.

Appreciation for reminders. One final theme deserves comment though it stands more independently. Twelve students who received gratitude texts expressed appreciation for these reminders. One student commented, "I LOVED getting texts from the 'gratitude fairy.' I really enjoyed getting little reminders to be grateful. Thank you." Seven students simply wrote "Thank you" while others elaborated-e.g., "Thank you for continually asking us to be grateful" and "It's a wonderful practice." Some students referenced other reminders that deepened gratitude-e.g., "My Gratitude Journal that sits by my bed reminds me to reflect back, notice blessings, and write them down." Another pointed to the role of professors in cultivating gratitude, "I loved when my professors would take time for us to be grateful at the beginning of class." These reminders (texts, journaling, time to pause in class) nudged students to ponder the broadening effect of gratitude. "I find that the reminders helped me start noticing blessings," explained a student; ". . . then I'm on a roll! It's almost like gratitude is contagious."

\section{Conclusion}

This study contributes to a growing body of scientific data on gratitude by exploring its cognitive benefits. When students intentionally practice gratitude toward learning, they tended to report better focus during class, while studying, or taking an exam. This increased focus may be linked to a more positive attitude about learning as well as a reduced stress level. Since college academics often produce stress, these findings are worth considering. Energy that might be taken up feeling stressed or anxious may be able to be redirect to focusing on and making sense of new information after a student mindfully chooses a grateful spirit. Another benefit for students who intentionally practice gratitude is experiencing added strength to sustain effort when learning feels challenging. This resilient spirit is rooted in students' appreciation that challenges can help them grow as learners. Thus, rather than closing down one's mind when faced with challenges, a student with a grateful spirit may view those challenges as an opportunity to learn.

These findings are worth educational consideration. Educators may want to consider embedding gratitude practices in classes in hopes of enhancing focus and resilience in learning. In this study, it is interesting to note that only the participants who received gratitude reminders in the form of text messages and self-identified that they intentionally practiced gratitude at least 3-5 times weekly experienced the benefits of increased focus and resilience in learning. Curiously, students who did not receive the reminders, but did express practicing gratitude at least 3-5 times weekly did not experience increased focus and resilience in learning. Perhaps the students who did not receive reminders were practicing gratitude in general terms, whereas the students who received the text reminders were nudged to practice gratitude specifically in relationship to learning. 
This observation points to the value of embedding gratitude practices in class that specifically encourage students to ponder the blessings of learning.

Educators should be aware, however, that not all students may experience positive benefits of gratitude practices. In this study participants who received the gratitude text reminders, but self-identified that they practiced gratitude less than once each week, did not experience benefits of increased focus and resilience in learning. Thus, while educators can encourage gratitude through providing time in class to contemplate and express gratitude related to learning (either orally or in writing), they cannot force a student to be grateful. Students need to intentionally choose to practice gratitude before they may experience increased focus and resilience in learning.

Though this study contributes to the growing body of research on gratitude by focusing specifically on the cognitive benefits, further research is needed. One limitation of this particular study relates to the drawbacks of self-reports used to measure increases in gratitude, focus, and resilience while learning. These self-reports are subjective in nature. Future research could utilize more objective measures to explore the impact of practicing gratitude on student's grades or the rate in which students choose to drop a class. Another limitation of this particular study relates to the timing of the administered inventory. The pre-intervention inventory was administered the week prior to the start of a semester (when students may experience increased optimism toward learning), whereas the post-intervention inventory was administered the week before finals (when students may experience increased stress toward learning). Future researchers will want to take the timing of inventory administration into consideration. With these limitations in mind, the results of this study are still encouraging. That is, though the inventory was re-administered during a time in the semester which can be particularly stressful, students who were reminded to practice gratitude toward learning throughout the semester and who selfreported intentionally doing so experienced increased focus and resilience in learning. This study serves as an encouragement to educators that providing time in class for students to ponder gratitude toward learning has the potential to strengthen students' level of gratitude, their ability to focus in class, and their ability to remain resilient when learning feels challenging.

\section{References}

Donaldson, S. I., Dollwet, M., \& Rao, M. A. (2015). Happiness, excellence, and optimal human functioning revisited: Examining the peer-reviewed literature linked to positive psychology. The Journal of Positive Psychology,10(3), 185-195.

doi:10.1080/17439760.2014.943801

Duckworth, A. L., \& Allred, K. M. (2012). Temperament in the classroom. In R.L. Shiner \& M. Zentner (Eds.), Handbook of Temperament (pp. 627-644). New York, NY: Guilford Press.

Duckworth, A. L., Peterson, C., Matthews, M. D., \& Kelly, D. R. (2007). Grit: Perseverance and passion for long-term goals. Journal of Personality and Social Psychology, 92(6), 1087. doi:10.1037/0022-3514.92.6.1087 
Duckworth, A., Steen, T. A., \& Seligman, M. E. (2005). Positive psychology in clinical practice. Annual Review Clinical Psychology. 1, 629-651.

doi:10.1146/annurev.clinpsy.1.102803.144154

Dweck, C. (2006). Mindset: The new psychology of success. New York: Random House.

Emmons, R. A. (2007). Thanks! How the new science of gratitude can make you happier. New York, NY: Houghton Mifflin Harcourt.

Emmons, R. A. (2014, June). Why does gratitude matter? Paper presented at the Greater Good Gratitude Summit, Richmond, CA.

Emmons, R. A., \& McCullough, M. E. (2003). Counting blessings versus burdens: an experimental investigation of gratitude and subjective well-being in daily life. Journal of personality and social psychology, 84(2), 377. doi:10.1037/0022-3514.84.2.377

Emmons, R. A., \& McCullough, M. E. (2004). The psychology of gratitude. New York, NY: Oxford University Press. doi:10.1093/acprof:oso/9780195150100.001.0001

Emmons, R. A., McCullough, M. E., \& Tsang, J. A. (2003). The assessment of gratitude. In Lopez, S. J., \& Snyder, C. R. (Eds.), Positive psychological assessment: A handbook of models and measures (pp. 327-341). Washington, DC: American Psychological Association. doi:10.1037/10612-021

Fredrickson, B. L. (2004). Gratitude, like other positive emotions, broadens and builds. In Emmons, R. A., \& McCullough, M. E. (Eds.). (pp. 145-166). The psychology of gratitude. New York, NY: Oxford University Press. doi:10.1093/acprof:oso/9780195150100.003.0008

Froh, J. J., Kashdan, T. B., Ozimkowski, K. M., \& Miller, N. (2009). Who benefits the most from a gratitude intervention in children and adolescents? Examining positive affect as a moderator. The Journal of Positive Psychology, 4(5), 408-422. doi:10.1080/17439760902992464

Froh, J. J., Miller, D. N., \& Snyder, S. F. (2007). Gratitude in children and adolescents: Development, assessment, and school-based intervention. School Psychology Forum 2(1). doi:10.1.1.183.3297

Howells, K. (2012). Gratitude in education. Rotterdam: Sense Publishers. doi:10.1007/978-94-6091-814-8

KIPP Public Charter Schools/Knowledge Is Power Program/Character Counts (n.d.). Retrieved March 23, 2016, from http://www.kipp.org/our-approach/character 
Lyubomirsky, S., Sheldon, K. M., \& Schkade, D. (2005). Pursuing happiness: The architecture of sustainable change. Review of General Psychology, 9(2), 111.

doi:10.1037/1089-2680.9.2.111

McCraty, R., \& Childre, D. (2004). The Grateful Heart: The Psychophysiology of Appreciation. In Emmons \& McCollough (Eds.) The psychology of gratitude, (230-255). New York, NY: Oxford University Press. doi:10.1093/acprof:oso/9780195150100.001.0001

Park, D., Tsukayama, E., Goodwin, G. P., Patrick, S., \& Duckworth, A. L (2015). A tripartite taxonomy of character: evidence for interpersonal, intrapersonal, and intellectual competencies in children. Manuscript submitted for publication.

Pellegrino, J. W., \& Hilton, M. L. (2012). Education for life and work: developing transferable knowledge and skills in the 21st century. Washington, DC: National Academy of Sciences. doi:10/17226/13398

Peterson, C., \& Seligman, M. E. (2004). Character strengths and virtues: A classification and handbook. Washington, DC: American Psychological Association.

Seligman, M. E. (2012). Flourish: A visionary new understanding of happiness and wellbeing. New York, NY: Simon and Schuster.

Seligman, M. E., Ernst, R. M., Gillham, J., Reivich, K., \& Linkins, M. (2009). Positive education: Positive psychology and classroom interventions. Oxford review of education, 35(3), 293-311. doi:10.1080/03054980902934563

Seligman, M. E. P., \& Csikszentmihalyi, M. (2000). Positive psychology: An introduction. American Psychologist, 55, 5-14. doi:10.1037/0003-066X.55.1.5

Seligman, M. E., Steen, T. A., Park, N., \& Peterson, C. (2005). Positive psychology progress: empirical validation of interventions. American psychologist, 60(5), 410. doi:10.1037/0003-066X.60.5.410

Strauss, A. L., \& Corbin, J. M. (1990). Basics of qualitative research (Vol. 15). Newbury Park, CA: Sage.

Tough, P. (2011). What if the Secret to Success is Failure?, New York Times Magazine, pp. 1-14.

Watkins, P. C., Cruz, L., Holben, H., \& Kolts, R. L. (2008). Taking care of business? Grateful processing of unpleasant memories. The Journal of Positive Psychology, 3(2), 87-99. doi:10.1080/17439760701760567

Watkins, P. C., Uhder, J., \& Pichinevskiy, S. (2014). Grateful recounting enhances subjective well-being: The importance of grateful processing. The Journal of Positive 
Psychology, 1-8. doi:10.1080/17439760.2014.927909

Wilson, J., \& Harris, P. (2015). Ripples of gratitude: The flow-on effect of practicing gratitude in the classroom. A Journal of the International Christian Community for Teacher Education, 10(1). Retrieved September 12, 2015, from http://icctejournal.org/issues/v10i1/v10i1-wilson-harris/

Wood, A. M., Froh, J. J., \& Geraghty, A. W. (2010). Gratitude and well-being: A review and theoretical integration. Clinical psychology review, 30(7), 890-905.

doi:10.1016/j.cpt.2010.03.005

Wood, A. M., Maltby, J., Gillett, R., Linley, P. A., \& Joseph, S. (2008). The role of gratitude in the development of social support, stress, and depression: Two longitudinal studies. Journal of Research in Personality, 42(4), 854-871. doi:10.1016/j.jrp.2007.11.003

Wood, A. M., Joseph, S., \& Maltby, J. (2009). Gratitude predicts psychological wellbeing above the big five facets. Personality and Individual Differences, 46(4), 443-447. doi:10.1016/j.paid.2008.11.012 